\title{
New iterative scheme with strict pseudo-contractions and multivalued nonexpansive mappings for fixed point problems and variational inequality problems
}

\author{
J Vahidi' , A Latif ${ }^{*}$ and M Eslamian ${ }^{1}$
}

"Correspondence: alatif@kau.edu.sa

${ }^{2}$ Department of Mathematics, King Abdulaziz University, P.O. Box 80203, Jeddah, 21589, Saudi Arabia Full list of author information is available at the end of the article

\begin{abstract}
In this paper, we introduce an iterative scheme for finding a common element of the sets of fixed points for multivalued nonexpansive mappings, strict pseudo-contractive mappings and the set of solutions of an equilibrium problem for a pseudomonotone, Lipschitz-type continuous bifunctions. We prove the strong convergence of the sequence, generated by the proposed scheme, to the solution of the variational inequality. Our results generalize and improve some known results.

MSC: $47 \mathrm{H} 10 ; 65 \mathrm{~K} 10 ; 65 \mathrm{~K} 15 ; 90 \mathrm{C} 25$
\end{abstract}

Keywords: Ky Fan inequality; strict pseudo-contractive mapping; multivalued nonexpansive mapping; common fixed point

\section{Introduction}

In 1967, Browder and Petryshyn [1] introduced a concept of strict pseudo-contractive in a real Hilbert space. Let $C$ be a nonempty subset of a real Hilbert space $H$, and let $T: C \rightarrow C$ be a single-valued mapping. A mapping $T$ is called a $\beta$-strict pseudo-contractive on $C$ [1] if there exists a constant $\beta \in[0,1)$ such that

$$
\|T x-T y\|^{2} \leq\|x-y\|^{2}+\beta\|(x-T x)-(y-T y)\|^{2}, \quad \forall x, y \in C .
$$

We use $F(T)$ to denote the set of all fixed points of $T ; F(T)=\{x \in C: x=T(x)\}$. Note that the class of strictly pseudo-contractive mappings strictly includes the class of nonexpansive mappings, which are the mappings $T$ on $C$ such that

$$
\|T x-T y\| \leq\|x-y\|
$$

for all $x, y \in C$ (see [2]). Strictly pseudocontractive mappings have more powerful applications than nonexpansive mappings in solving inverse problems, see Scherzer [3]. In the literature, many interesting and important results have been appeared to approximate the fixed points of pseudo-contractive mappings. For example, see [4-6] and the references therein.

(c) 2013 Vahidi et al.; licensee Springer. This is an Open Access article distributed under the terms of the Creative Commons Attribution License (http://creativecommons.org/licenses/by/2.0), which permits unrestricted use, distribution, and reproduction in any medium, provided the original work is properly cited. 
A subset $C \subset H$ is called proximal if for each $x \in H$, there exists an element $y \in C$ such that

$$
\|x-y\|=\operatorname{dist}(x, C)=\inf \{\|x-z\|: z \in C\} .
$$

We denote by $C B(C), K(C)$ and $P(C)$ the collection of all nonempty closed bounded subsets, nonempty compact subsets, and nonempty proximal bounded subsets of $C$, respectively. The Hausdorff metric $H$ on $C B(H)$ is defined by

$$
H(A, B):=\max \left\{\sup _{x \in A} \operatorname{dist}(x, B), \sup _{y \in B} \operatorname{dist}(y, A)\right\}
$$

for all $A, B \in C B(H)$.

Let $T: H \rightarrow 2^{H}$ be a multivalued mapping. An element $x \in H$ is said to be a fixed point of $T$ if $x \in T x$. A multivalued mapping $T: H \rightarrow C B(H)$ is called nonexpansive if

$$
H(T x, T y) \leq\|x-y\|, \quad x, y \in H .
$$

Much work has been done on the existence of common fixed points for a pair consisting of a single-valued and a multivalued mapping, see, for instance [7-14]. Let $f$ be a bifunction from $C \times C$ into $\mathbb{R}$, such that $f(x, x)=0$ for all $x \in C$. Consider the classical Ky Fan inequality. Find a point $x^{*} \in C$ such that

$$
f\left(x^{*}, y\right) \geq 0, \quad \forall y \in C,
$$

where $f(x, \cdot)$ is convex and subdifferentiable on $C$ for every $x \in C$. The set of solutions for this problem is denoted by $\operatorname{Sol}(f, C)$. In fact, the Ky Fan inequality can be formulated as an equilibrium problem. Further, if $f(x, y)=\langle F x, y-x\rangle$ for every $x, y \in C$, where $F$ is a mapping from $C$ into $H$, then the Ky Fan inequality problem (equilibrium problem) becomes the classical variational inequality problem, which is formulated as finding a point $x^{*} \in C$ such that

$$
\left\langle F x^{*}, y-x^{*}\right\rangle \geq 0, \quad \forall y \in C .
$$

Such problems arise frequently in mathematics, physics, engineering, game theory, transportation, economics and network. Due to importance of the solutions of such problems, many researchers are working in this area and studying on the existence of the solutions of such problems, see, e.g., [15-20]. Further, in the recent years, iterative algorithms for finding a common element of the set of solutions of equilibrium problem and the set of fixed points of nonexpansive mappings in a real Hilbert space have been studied by many authors (see, e.g., [21-33]).

Definition 1.1 Let $C$ be a nonempty closed convex subset of a Hilbert space $H$. The bifunction $f: C \times C \rightarrow \mathbb{R}$ is said to be

(i) strongly monotone on $C$ with $\alpha>0$ if

$$
f(x, y)+f(y, x) \leq-\alpha\|x-y\|^{2}, \quad \forall x, y \in C
$$


(ii) monotone on $C$ if

$$
f(x, y)+f(y, x) \leq 0, \quad \forall x, y \in C ;
$$

(iii) pseudomonotone on $C$ if

$$
f(x, y) \geq 0 \Rightarrow f(y, x) \leq 0, \quad \forall x, y \in C ;
$$

(iv) Lipschitz-type continuous on $C$ with constants $c_{1}>0$ and $c_{2}>0$ (in the sense of Mastroeni [34]) if

$$
f(x, y)+f(y, z) \geq f(x, z)-c_{1}\|x-y\|^{2}-c_{2}\|y-z\|^{2}, \quad \forall x, y, z \in C .
$$

Recently, Anh $[35,36]$ introduced some methods for finding a common element of the set of solutions of monotone Lipschitz-type continuous equilibrium problem and the set of fixed points of a nonexpansive mapping $T$ in a Hilbert space $H$. In [35], he proved the following theorem.

Theorem 1.2 Let $C$ be a nonempty, closed, and convex subset of a real Hilbert space H. Let $f: C \times C \rightarrow \mathbb{R}$ be a monotone, continuous, and Lipschitz-type continuous bifunction, and let $f(x, \cdot)$ be convex and subdifferentiable on $C$ for every $x \in C$. Let $h$ be a contraction of $C$ into itself with constant $k \in(0,1)$, let $S$ be a nonexpansive mapping of $C$ into itself, and let $F(S) \cap \operatorname{Sol}(f, C) \neq \emptyset$. Let $\left\{x_{n}\right\},\left\{w_{n}\right\}$ and $\left\{z_{n}\right\}$ be sequences generated by $x_{0} \in C$ and by

$$
\left\{\begin{array}{l}
w_{n}=\arg \min \left\{\lambda_{n} f\left(x_{n}, w\right)+\frac{1}{2}\left\|w-x_{n}\right\|^{2}: w \in C\right\}, \\
z_{n}=\arg \min \left\{\lambda_{n} f\left(w_{n}, z\right)+\frac{1}{2}\left\|z-x_{n}\right\|^{2}: z \in C\right\}, \\
x_{n+1}=\alpha_{n} h\left(x_{n}\right)+\beta_{n} x_{n}+\gamma_{n}\left(\mu S\left(x_{n}\right)+(1-\mu) z_{n}\right), \quad \forall n \geq 0,
\end{array}\right.
$$

where $\mu \in(0,1)$, and $\left\{\alpha_{n}\right\},\left\{\beta_{n}\right\},\left\{\gamma_{n}\right\}$, and $\left\{\lambda_{n}\right\}$ satisfy the following conditions:

(i) $\lim _{n \rightarrow \infty} \alpha_{n}=0, \sum_{n=1}^{\infty} \alpha_{n}=\infty$,

(ii) $\lim _{n \rightarrow \infty}\left|\lambda_{n+1}-\lambda_{n}\right|=0,\left\{\lambda_{n}\right\} \subset[a, b] \subset\left(0, \frac{1}{L}\right)$, where $L=\max \left\{2 c_{1}, 2 c_{2}\right\}$,

(iii) $\alpha_{n}+\beta_{n}+\gamma_{n}=1$ and $\alpha_{n}\left(2-\alpha_{n}-2 \beta_{n} k-2 \gamma_{n}\right) \in(0,1)$,

(iv) $0<\liminf _{n \rightarrow \infty} \beta_{n} \leq \limsup _{n \rightarrow \infty} \beta_{n}<1$.

Then, the sequences $\left\{x_{n}\right\},\left\{w_{n}\right\}$ and $\left\{z_{n}\right\}$ converge strongly to $q \in F(S) \cap \operatorname{Sol}(f, C)$ which solves the variational inequality

$$
\langle(I-h) q, x-q\rangle \geq 0, \quad \forall x \in F(S) \cap \operatorname{Sol}(f, C) .
$$

In this paper, we introduce an iterative algorithm for finding a common element of the sets of fixed points for multivalued nonexpansive mappings, strict pseudo-contractive mappings and the set of solutions of an equilibrium problem for a pseudomonotone, Lipschitz-type continuous bifunctions. We prove the strong convergence of the sequence generated by the proposed algorithm to the solution of the variational inequality. Our results generalize and improve a number of known results including the results of Anh [35]. 


\section{Preliminaries}

Let $H$ be a real Hilbert space with inner product $\langle\cdot, \cdot\rangle$ and the norm $\|\cdot\|$. Let $\left\{x_{n}\right\}$ be a sequence in $H$, and let $x \in H$. Weak convergence of $\left\{x_{n}\right\}$ to $x$ is denoted by $x_{n} \rightarrow x$, and strong convergence by $x_{n} \rightarrow x$. Let $C$ be a nonempty closed convex subset of $H$. The nearest point projection from $H$ to $C$, denoted by $\operatorname{Proj}_{C}$, assigns to each $x \in H$ the unique point $\operatorname{Proj}_{C} x \in C$ with the property

$$
\left\|x-\operatorname{Proj}_{C} x\right\|:=\inf \{\|x-y\|, \forall y \in C\} .
$$

It is known that $\operatorname{Proj}_{C}$ is a nonexpansive mapping, and for each $x \in H$,

$$
\left\langle x-\operatorname{Proj}_{C} x, y-\operatorname{Proj}_{C} x\right\rangle \leq 0, \quad \forall y \in C .
$$

Definition 2.1 Let $C$ be a nonempty, closed and convex subset of a Hilbert space $H$. Denote by $N_{C}(v)$ the normal cone of $C$ at $v \in C$, i.e.,

$$
N_{C}(v):=\{z \in H:\langle z, y-v\rangle \leq 0, \forall y \in C\} .
$$

Definition 2.2 Let $C$ be a nonempty, closed and convex subset of a Hilbert space $H$, and let $f: C \times C \rightarrow \mathbb{R}$ be a bifunction. For each $z \in C$, by $\partial_{2} f(z, u)$ we denote the subgradient of the function $f(z, \cdot)$ at $u$, i.e.,

$$
\partial_{2} f(z, u)=\{\xi \in H: f(z, t)-f(z, u) \geq\langle\xi, t-u\rangle, \forall t \in C\} .
$$

The following lemmas are crucial for the proofs of our results.

Lemma 2.3 In a Hilbert space $H$, the following inequality holds:

$$
\|x+y\|^{2} \leq\|x\|^{2}+2\langle y, x+y\rangle, \quad \forall x, y \in H .
$$

Lemma 2.4 [37] Let $\left\{a_{n}\right\}$ be a sequence of nonnegative real numbers, let $\left\{\alpha_{n}\right\}$ be a sequence in $(0,1)$ with $\sum_{n=1}^{\infty} \alpha_{n}=\infty$, let $\left\{\gamma_{n}\right\}$ be a sequence of nonnegative real numbers with $\sum_{n=1}^{\infty} \gamma_{n}<\infty$, and let $\left\{\beta_{n}\right\}$ be a sequence of real numbers with $\lim _{\sup _{n \rightarrow \infty}} \beta_{n} \leq 0$. Suppose that the following inequality holds:

$$
a_{n+1} \leq\left(1-\alpha_{n}\right) a_{n}+\alpha_{n} \beta_{n}+\gamma_{n}, \quad n \geq 0 .
$$

Then $\lim _{n \rightarrow \infty} a_{n}=0$.

Lemma 2.5 [38] Let $H$ be a real Hilbert space. Then for all $x, y, z \in H$ and $\alpha, \beta, \gamma \in[0,1]$ with $\alpha+\beta+\gamma=1$, we have

$$
\|\alpha x+\beta y+\gamma z\|^{2}=\alpha\|x\|^{2}+\beta\|y\|^{2}+\gamma\|z\|^{2}-\alpha \beta\|x-y\|^{2}-\alpha \gamma\|x-z\|^{2}-\beta \gamma\|z-y\|^{2} .
$$

Lemma 2.6 [39] Let $\left\{t_{n}\right\}$ be a sequence of real numbers such that there exists a subsequence $\left\{n_{i}\right\}$ of $\{n\}$ such that $t_{n_{i}}<t_{n_{i}+1}$ for all $i \in \mathbb{N}$. Then there exists a nondecreasing sequence 
$\{\tau(n)\} \subset \mathbb{N}$ such that $\tau(n) \rightarrow \infty$, and the following properties are satisfied by all (sufficiently large) numbers $n \in \mathbb{N}$ :

$$
t_{\tau(n)} \leq t_{\tau(n)+1}, \quad t_{n} \leq t_{\tau(n)+1} .
$$

In fact,

$$
\tau(n)=\max \left\{k \leq n: t_{k}<t_{k+1}\right\} .
$$

Lemma 2.7 [36] Let $C$ be a nonempty closed convex subset of a real Hilbert space $H$, and let $f: C \times C \rightarrow \mathbb{R}$ be a pseudomonotone and Lipschitz-type continuous bifunction. For each $x \in C$, let $f(x, \cdot)$ be convex and subdifferentiable on $C$. Let $\left\{x_{n}\right\},\left\{z_{n}\right\}$ and $\left\{w_{n}\right\}$ be the sequences, generated by $x_{0} \in C$ and by

$$
\left\{\begin{array}{l}
w_{n}=\arg \min \left\{\lambda_{n} f\left(x_{n}, w\right)+\frac{1}{2}\left\|w-x_{n}\right\|^{2}: w \in C\right\}, \\
z_{n}=\arg \min \left\{\lambda_{n} f\left(w_{n}, z\right)+\frac{1}{2}\left\|z-x_{n}\right\|^{2}: z \in C\right\} .
\end{array}\right.
$$

Then for each $x^{*} \in \operatorname{Sol}(f, C)$,

$$
\left\|z_{n}-x^{*}\right\|^{2} \leq\left\|x_{n}-x^{*}\right\|^{2}-\left(1-2 \lambda_{n} c_{1}\right)\left\|x_{n}-w_{n}\right\|^{2}-\left(1-2 \lambda_{n} c_{2}\right)\left\|w_{n}-z_{n}\right\|^{2}, \quad \forall n \geq 0 .
$$

Lemma 2.8 [5] Let $C$ be nonempty closed convex subset of a real Hilbert space $H$, and let $T: C \rightarrow C$ be $\beta$-pseudo-contraction mapping. Then $I-T$ is demiclosed at 0 . That is, if $\left\{x_{n}\right\}$ is a sequence in $C$ such that $x_{n} \rightarrow x$ and $\lim _{n \rightarrow \infty}\left\|x_{n}-T x_{n}\right\|=0$, then $x=T x$.

Lemma 2.9 [5] Let $C$ be a closed convex subset of a Hilbert space $H$, and let $T: C \rightarrow C$ be a $\beta$-strict pseudo-contraction on $C$ and the fixed-point set $F(T)$ of $T$ is nonempty, then $F(T)$ is closed and convex.

Lemma 2.10 [40] Let $C$ be a closed convex subset of a real Hilbert space H. Let $T: C \rightarrow$ $C B(C)$ be a nonexpansive multivalued mapping. Assume that $T(p)=\{p\}$ for all $p \in F(T)$. Then $F(T)$ is closed and convex.

Lemma 2.11 [25] Let $C$ be a nonempty closed convex subset of a real Hilbert space $H$. Let $T: C \rightarrow K(C)$ be a nonexpansive multivalued mapping. If $x_{n} \rightarrow v$ and $\lim _{n \rightarrow \infty} \operatorname{dist}\left(x_{n}\right.$, $\left.T x_{n}\right)=0$, then $v \in T v$.

\section{Main results}

Now, we are in a position to give our main results.

Theorem 3.1 Let $C$ be a nonempty closed convex subset of a real Hilbert space $H$, and let $f: C \times C \rightarrow \mathbb{R}$ be a monotone, continuous, and Lipschitz-type continuous bifunction. Suppose that $f(x, \cdot)$ is convex and subdifferentiable on $C$ for all $x \in C$. Let, $T: C \rightarrow C B(C)$ be a multivalued nonexpansive mapping, and let $S: C \rightarrow C$ be a $\beta$-strict pseudo-contraction mapping. Assume that $\mathcal{F}=F(T) \cap F(S) \cap \operatorname{Sol}(f, C) \neq \emptyset$ and $T(p)=\{p\}$ for each $p \in \mathcal{F}$. Let $h$ 
be a $k$-contraction of $C$ into itself. Let $\left\{x_{n}\right\},\left\{w_{n}\right\}$ and $\left\{z_{n}\right\}$ be sequences generated by $x_{0} \in C$ and by

$$
\left\{\begin{array}{l}
w_{n}=\arg \min \left\{\lambda_{n} f\left(x_{n}, w\right)+\frac{1}{2}\left\|w-x_{n}\right\|^{2}: w \in C\right\}, \\
z_{n}=\arg \min \left\{\lambda_{n} f\left(w_{n}, z\right)+\frac{1}{2}\left\|z-x_{n}\right\|^{2}: z \in C\right\}, \\
y_{n}=\alpha_{n} z_{n}+\beta_{n} u_{n}+\gamma_{n} S z_{n}, \\
x_{n+1}=\vartheta_{n} h\left(x_{n}\right)+\left(1-\vartheta_{n}\right) y_{n}, \quad \forall n \geq 0,
\end{array}\right.
$$

where $u_{n} \in T z_{n}$. Let $\left\{\alpha_{n}\right\},\left\{\beta_{n}\right\},\left\{\gamma_{n}\right\},\left\{\lambda_{n}\right\}$ and $\left\{\vartheta_{n}\right\}$ satisfy the following conditions:

(i) $\left\{\vartheta_{n}\right\} \subset(0,1), \lim _{n \rightarrow \infty} \vartheta_{n}=0, \sum_{n=1}^{\infty} \vartheta_{n}=\infty$,

(ii) $\left\{\lambda_{n}\right\} \subset[a, b] \subset\left(0, \frac{1}{L}\right)$, where $L=\max \left\{2 c_{1}, 2 c_{2}\right\}$,

(iii) $\left\{\alpha_{n}\right\},\left\{\gamma_{n}\right\} \subset[a, 1) \subset(0,1), \alpha_{n}>\beta$ and $\alpha_{n}+\beta_{n}+\gamma_{n}=1$.

Then, the sequence $\left\{x_{n}\right\}$ converges strongly to $q \in \mathcal{F}$, which solves the variational inequality

$$
\langle q-h q, x-q\rangle \geq 0, \quad \forall x \in \mathcal{F} .
$$

Proof Let $Q=\operatorname{Proj}_{\mathcal{F}}$. It easy to see that $Q h$ is a contraction. By the Banach contraction principle, there exists a $q \in \mathcal{F}$ such that $q=(Q h)(q)$. Applying Lemma 2.7, we have

$$
\left\|z_{n}-q\right\|^{2} \leq\left\|x_{n}-q\right\|^{2}-\left(1-2 \lambda_{n} c_{1}\right)\left\|x_{n}-w_{n}\right\|^{2}-\left(1-2 \lambda_{n} c_{2}\right)\left\|w_{n}-z_{n}\right\|^{2} .
$$

This implies that

$$
\left\|z_{n}-q\right\| \leq\left\|x_{n}-q\right\|
$$

Since $T$ is nonexpansive and $T q=\{q\}$, by (4) we have

$$
\left\|u_{n}-q\right\|=\operatorname{dist}\left(u_{n}, T q\right) \leq H\left(T z_{n}, T q\right) \leq\left\|z_{n}-q\right\| \leq\left\|x_{n}-q\right\| .
$$

We show that $\left\{x_{n}\right\}$ is bounded. Indeed, using inequality (4), (5) and Lemma 2.5, we have

$$
\begin{aligned}
\left\|y_{n}-q\right\|^{2}= & \left\|\alpha_{n} z_{n}+\beta_{n} u_{n}+\gamma_{n} S z_{n}-q\right\|^{2} \\
\leq & \alpha_{n}\left\|z_{n}-q\right\|^{2}+\beta_{n}\left\|u_{n}-q\right\|^{2}+\gamma_{n}\left\|S z_{n}-q\right\|^{2} \\
& -\alpha_{n} \beta_{n}\left\|u_{n}-z_{n}\right\|^{2}-\alpha_{n} \gamma_{n}\left\|z_{n}-S z_{n}\right\|^{2} \\
\leq & \alpha_{n}\left\|x_{n}-q\right\|^{2}+\beta_{n}\left\|x_{n}-q\right\|^{2}+\gamma_{n}\left(\left\|z_{n}-q\right\|^{2}+\beta\left\|z_{n}-S z_{n}\right\|^{2}\right) \\
& -\alpha_{n} \beta_{n}\left\|u_{n}-z_{n}\right\|^{2}-\alpha_{n} \gamma_{n}\left\|z_{n}-S z_{n}\right\|^{2} \\
& -\alpha_{n}\left(1-2 \lambda_{n} c_{1}\right)\left\|x_{n}-w_{n}\right\|^{2}-\alpha_{n}\left(1-2 \lambda_{n} c_{2}\right)\left\|w_{n}-z_{n}\right\|^{2} \\
\leq & \left\|x_{n}-q\right\|^{2}-\alpha_{n} \beta_{n}\left\|u_{n}-z_{n}\right\|^{2}-\gamma_{n}\left(\alpha_{n}-\beta\right)\left\|z_{n}-S z_{n}\right\|^{2} \\
& -\alpha_{n}\left(1-2 \lambda_{n} c_{1}\right)\left\|x_{n}-w_{n}\right\|^{2}-\alpha_{n}\left(1-2 \lambda_{n} c_{2}\right)\left\|w_{n}-z_{n}\right\|^{2} .
\end{aligned}
$$

It follows that

$$
\left\|y_{n}-q\right\|^{2} \leq\left\|x_{n}-q\right\|^{2}-\gamma_{n}\left(\alpha_{n}-\beta\right)\left\|z_{n}-S z_{n}\right\|^{2} .
$$


Since $\alpha_{n}>\beta$, we get that $\left\|y_{n}-q\right\| \leq\left\|x_{n}-q\right\|$. This implies that

$$
\begin{aligned}
\left\|x_{n+1}-q\right\| & =\left\|\vartheta_{n} h x_{n}+\left(1-\vartheta_{n}\right) y_{n}-q\right\| \\
& \leq \vartheta_{n}\left\|h x_{n}-q\right\|+\left(1-\vartheta_{n}\right)\left\|y_{n}-q\right\| \\
& \leq \vartheta_{n}\left(\left\|h x_{n}-h q\right\|+\|h q-q\|\right)+\left(1-\vartheta_{n}\right)\left\|x_{n}-q\right\| \\
& \leq \vartheta_{n} k\left\|x_{n}-q\right\|+\vartheta_{n}\|h q-q\|+\left(1-\vartheta_{n}\right)\left\|x_{n}-q\right\| \\
& =\left(1-\vartheta_{n}(1-k)\right)\left\|x_{n}-q\right\|+\vartheta_{n}\|h q-q\| \\
& \leq \max \left\{\left\|x_{n}-q\right\|, \frac{\|h q-q\|}{1-k}\right\} .
\end{aligned}
$$

By induction, we get

$$
\left\|x_{n}-q\right\| \leq \max \left\{\left\|x_{0}-q\right\|, \frac{\|h q-q\|}{1-k}\right\}
$$

for all $n \in \mathbb{N}$. This implies that $\left\{x_{n}\right\}$ is bounded, and we also obtain that $\left\{u_{n}\right\},\left\{z_{n}\right\},\left\{h x_{n}\right\}$ and $\left\{S z_{n}\right\}$ are bounded. Next, we show that

$$
\lim _{n \rightarrow \infty}\left\|z_{n}-S z_{n}\right\|=\lim _{n \rightarrow \infty}\left\|z_{n}-u_{n}\right\|=\lim _{n \rightarrow \infty}\left\|z_{n}-x_{n}\right\|=0 .
$$

Indeed, using inequality (6), we have

$$
\begin{aligned}
\left\|x_{n+1}-q\right\|^{2}= & \left\|\vartheta_{n} h x_{n}+\left(1-\vartheta_{n}\right) y_{n}-q\right\|^{2} \\
\leq & \vartheta_{n}\left\|h x_{n}-q\right\|^{2}+\left(1-\vartheta_{n}\right)\left\|y_{n}-q\right\|^{2} \\
\leq & \vartheta_{n}\left\|h x_{n}-q\right\|^{2}+\left(1-\vartheta_{n}\right)\left\|x_{n}-p\right\|^{2} \\
& -\left(1-\vartheta_{n}\right) \alpha_{n} \beta_{n}\left\|u_{n}-z_{n}\right\|^{2}-\left(1-\vartheta_{n}\right) \gamma_{n}\left(\alpha_{n}-\beta\right)\left\|z_{n}-S z_{n}\right\|^{2} \\
& -\left(1-\vartheta_{n}\right) \alpha_{n}\left(1-2 \lambda_{n} c_{1}\right)\left\|x_{n}-w_{n}\right\|^{2}-\left(1-\vartheta_{n}\right) \alpha_{n}\left(1-2 \lambda_{n} c_{2}\right)\left\|w_{n}-z_{n}\right\|^{2} .
\end{aligned}
$$

Therefore, we have

$$
\left(1-\vartheta_{n}\right) \gamma_{n}\left(\alpha_{n}-\beta\right)\left\|z_{n}-S z_{n}\right\|^{2} \leq\left\|x_{n}-q\right\|^{2}-\left\|x_{n+1}-q\right\|^{2}+\vartheta_{n}\left\|h x_{n}-q\right\| .
$$

In order to prove that $x_{n} \rightarrow q$ as $n \rightarrow \infty$, we consider the following two cases.

Case 1. Suppose that there exists $n_{0}$ such that $\left\{\left\|x_{n}-q\right\|\right\}$ is nonincreasing, for all $n \geq n_{0}$. Boundedness of $\left\{\left\|x_{n}-q\right\|\right\}$ implies that $\left\|x_{n}-q\right\|$ is convergent. Since $\left\{h x_{n}\right\}$ is bounded and $\lim _{n \rightarrow \infty} \vartheta_{n}=0$, from (7) and our assumption that $\alpha_{n}>\beta$, we obtain that

$$
\lim _{n \rightarrow \infty}\left\|z_{n}-S z_{n}\right\|=0
$$

By similar argument we can obtain that

$$
\lim _{n \rightarrow \infty}\left\|u_{n}-z_{n}\right\|=\lim _{n \rightarrow \infty}\left\|x_{n}-w_{n}\right\|=\lim _{n \rightarrow \infty}\left\|w_{n}-z_{n}\right\|=0 .
$$


From this with inequality $\left\|x_{n}-z_{n}\right\| \leq\left\|x_{n}-w_{n}\right\|+\left\|w_{n}-z_{n}\right\|$, it follows that

$$
\lim _{n \rightarrow \infty}\left\|x_{n}-z_{n}\right\|=0
$$

Next, we show that

$$
\limsup _{n \rightarrow \infty}\left\langle q-h q, q-x_{n}\right\rangle \leq 0
$$

where $q=(Q h)(q)$. To show this inequality, we choose a subsequence $\left\{x_{n_{i}}\right\}$ of $\left\{x_{n}\right\}$ such that

$$
\lim _{i \rightarrow \infty}\left\langle q-h q, q-x_{n_{i}}\right\rangle=\limsup _{n \rightarrow \infty}\left\langle q-h q, q-x_{n}\right\rangle .
$$

Since $\left\{x_{n_{i}}\right\}$ is bounded, there exists a subsequence $\left\{x_{n_{i}}\right\}$ of $\left\{x_{n_{i}}\right\}$, which converges weakly to $x^{*}$. Without loss of generality, we can assume that $x_{n_{i}} \rightarrow x^{*}$. From inequality (9), we have $z_{n_{i}} \rightarrow x^{*}$. Now, since $\lim _{n \rightarrow \infty}\left\|z_{n}-S z_{n}\right\|=0$, from Lemma 2.8, we have $x^{*} \in F(S)$. Also from (8), we have

$$
\operatorname{dist}\left(z_{n}, T z_{n}\right) \leq\left\|u_{n}-z_{n}\right\| \rightarrow 0 \quad \text { as } n \rightarrow \infty
$$

It follows from Lemma 2.9 that $x^{*} \in F(T)$. Now, we show that $x^{*} \in \operatorname{Sol}(f, C)$. Since $f(x, \cdot)$ is convex on $C$ for each $x \in C$, we see that

$$
w_{n}=\arg \min \left\{\lambda_{n} f\left(x_{n}, y\right)+\frac{1}{2}\left\|y-x_{n}\right\|^{2}: y \in C\right\}
$$

if and only if

$$
o \in \partial_{2}\left(f\left(x_{n}, y\right)+\frac{1}{2}\left\|y-x_{n}\right\|^{2}\right)\left(w_{n}\right)+N_{C}\left(w_{n}\right)
$$

where $N_{C}(x)$ is the (outward) normal cone of $C$ at $x \in C$. This follows that

$$
0=\lambda_{n} v+w_{n}-x_{n}+u_{n},
$$

where $v \in \partial_{2} f\left(x_{n}, w_{n}\right)$ and $u_{n} \in N_{C}\left(w_{n}\right)$. By the definition of the normal cone $N_{C}$, we have

$$
\left\langle w_{n}-x_{n}, y-w_{n}\right\rangle \geq \lambda_{n}\left\langle v, w_{n}-y\right\rangle, \quad \forall y \in C .
$$

Since $f\left(x_{n}, \cdot\right)$ is subdifferentiable on $C$, there exists $v \in \partial_{2} f\left(x_{n}, w_{n}\right)$ such that

$$
f\left(x_{n}, y\right)-f\left(x_{n}, w_{n}\right) \geq\left\langle v, y-w_{n}\right\rangle, \quad \forall y \in C
$$

(see, $[41,42])$. Combining this with (10), we have

$$
\lambda_{n}\left(f\left(x_{n}, y\right)-f\left(x_{n}, w_{n}\right)\right) \geq\left\langle w_{n}-x_{n}, w_{n}-y\right\rangle, \quad \forall y \in C .
$$


Hence

$$
f\left(x_{n_{i}}, y\right)-f\left(x_{n_{i}}, w_{n_{i}}\right) \geq \frac{1}{\lambda_{n_{i}}}\left\langle w_{n_{i}}-x_{n_{i}}, w_{n_{i}}-y\right\rangle, \quad \forall y \in C .
$$

From (8), we have that $w_{n_{i}} \rightarrow x^{*}$. Now by continuity of $f$ and assumption that $\left\{\lambda_{n}\right\} \subset$ $[a, b] \subset] 0, \frac{1}{L}[$, we have

$$
f\left(x^{*}, y\right) \geq 0, \quad \forall y \in C
$$

This implies that $x^{*} \in \operatorname{Sol}(f, C)$, and hence $x^{*} \in \mathcal{F}$. Since $q=(Q h)(q)$ and $x^{*} \in \mathcal{F}$, it follows that

$$
\limsup _{n \rightarrow \infty}\left\langle q-h q, q-x_{n}\right\rangle=\lim _{i \rightarrow \infty}\left\langle q-h q, q-x_{n_{i}}\right\rangle=\left\langle q-h q, q-x^{*}\right\rangle \leq 0
$$

By using Lemma 2.3 and inequality (6), we have

$$
\begin{aligned}
\left\|x_{n+1}-q\right\|^{2} \leq & \left\|\left(1-\vartheta_{n}\right)\left(y_{n}-q\right)\right\|^{2}+2 \vartheta_{n}\left\langle h x_{n}-q, x_{n+1}-q\right\rangle \\
\leq & \left(1-\vartheta_{n}\right)^{2}\left\|y_{n}-q\right\|^{2}+2 \vartheta_{n}\left\langle h x_{n}-h q, x_{n+1}-q\right\rangle+2 \vartheta_{n}\left\langle h q-q, x_{n+1}-q\right\rangle \\
\leq & \left(1-\vartheta_{n}\right)^{2}\left\|x_{n}-q\right\|^{2}+2 \vartheta_{n} k\left\|x_{n}-q\right\|\left\|x_{n+1}-q\right\|+2 \vartheta_{n}\left\langle h q-q, x_{n+1}-q\right\rangle \\
\leq & \left(1-\vartheta_{n}\right)^{2}\left\|x_{n}-q\right\|^{2}+\vartheta_{n} k\left(\left\|x_{n}-q\right\|^{2}+\left\|x_{n+1}-q\right\|^{2}\right) \\
& +2 \vartheta_{n}\left\langle h q-q, x_{n+1}-q\right\rangle \\
\leq & \left(\left(1-\vartheta_{n}\right)^{2}+\vartheta_{n} k\right)\left\|x_{n}-q\right\|^{2}+\vartheta_{n} k\left\|x_{n+1}-q\right\|^{2}+2 \vartheta_{n}\left\langle h q-q, x_{n+1}-q\right\rangle .
\end{aligned}
$$

This implies that

$$
\begin{aligned}
\left\|x_{n+1}-q\right\|^{2} \leq & \left(1-\frac{2(1-k) \vartheta_{n}}{1-\vartheta_{n} k}\right)\left\|x_{n}-q\right\|^{2}+\frac{\vartheta_{n}^{2}}{1-\vartheta_{n} k}\left\|x_{n}-q\right\|^{2} \\
& +\frac{2 \vartheta_{n}}{1-\vartheta_{n} k}\left\langle h q-q, x_{n+1}-q\right\rangle .
\end{aligned}
$$

From Lemma 2.4, we conclude that the sequence $\left\{x_{n}\right\}$ converges strongly to $q$.

Case 2. Assume that there exists a subsequence $\left\{x_{n_{j}}\right\}$ of $\left\{x_{n}\right\}$ such that

$$
\left\|x_{n_{j}}-q\right\|<\left\|x_{n_{j+1}}-q\right\|
$$

for all $j \in \mathbb{N}$. In this case from Lemma 2.6, there exists a nondecreasing sequence $\{\tau(n)\}$ of $\mathbb{N}$ for all $n \geq n_{0}$ (for some $n_{0}$ large enough) such that $\tau(n) \rightarrow \infty$ as $n \rightarrow \infty$, and the following inequalities hold for all $n \geq n_{0}$,

$$
\left\|x_{\tau(n)}-q\right\|<\left\|x_{\tau(n)+1}-q\right\|, \quad\left\|x_{n}-q\right\|<\left\|x_{\tau(n)+1}-q\right\| .
$$

From (3), we obtain $\lim _{n \rightarrow \infty}\left\|z_{\tau(n)}-S z_{\tau(n)}\right\|=0$, and similarly we obtain

$$
\lim _{n \rightarrow \infty}\left\|x_{\tau(n)}-z_{\tau(n)}\right\|=\lim _{n \rightarrow \infty}\left\|u_{\tau(n)}-z_{\tau(n)}\right\|=0 .
$$


Following an argument similar to that in Case 1, we have

$$
\lim _{n \rightarrow \infty}\left\|x_{\tau(n)}-q\right\|=0, \quad \lim _{n \rightarrow \infty}\left\|x_{\tau(n)+1}-q\right\|=0 .
$$

Thus, by Lemma 2.6, we have

$$
0 \leq\left\|x_{n}-q\right\| \leq \max \left\{\left\|x_{\tau(n)}-q\right\|,\left\|x_{n}-q\right\|\right\} \leq\left\|x_{\tau(n)+1}-q\right\| .
$$

Therefore, $\left\{x_{n}\right\}$ converges strongly to $q \in \mathcal{F}$. This completes the proof.

Now, let $T: C \rightarrow P(C)$ be a multivalued mapping, and let

$$
P_{T}(x)=\{y \in T x:\|x-y\|=\operatorname{dist}(x, T x)\}, \quad x \in C .
$$

Then, we have $F(T)=F\left(P_{T}\right)$. Indeed, if $p \in F(T)$, then $P_{T}(p)=\{p\}$, hence $p \in F\left(P_{T}\right)$. On the other hand, if $p \in F\left(P_{T}\right)$, since $P_{T}(p) \subset T p$, we have $p \in F(T)$. Now, using the similar arguments as in the proof of Theorem 3.1, we obtain the following result by replacing $T$ by $P_{T}$, and removing the strict condition $T(p)=\{p\}$ for all $p \in F(T)$.

Theorem 3.2 Let $C$ be a nonempty closed convex subset of a real Hilbert space $H$, and let $f: C \times C \rightarrow \mathbb{R}$ be a monotone, continuous, and Lipschitz-type continuous bifunction. Suppose that $f(x, \cdot)$ is convex and subdifferentiable on $C$ for all $x \in C$. Let $T: C \rightarrow P(C)$ be a multivalued mapping such that $P_{T}$ is nonexpansive, and let $S: C \rightarrow C$ be a $\beta$-strict pseudo-contraction mapping. Assume that $\mathcal{F}=F(T) \cap F(S) \cap \operatorname{Sol}(f, C) \neq \emptyset$. Let $h$ be a $k$ contraction of $C$ into itself. Let $\left\{x_{n}\right\},\left\{w_{n}\right\}$ and $\left\{z_{n}\right\}$ be sequences generated by $x_{0} \in C$ and by

$$
\left\{\begin{array}{l}
w_{n}=\arg \min \left\{\lambda_{n} f\left(x_{n}, w\right)+\frac{1}{2}\left\|w-x_{n}\right\|^{2}: w \in C\right\}, \\
z_{n}=\arg \min \left\{\lambda_{n} f\left(w_{n}, z\right)+\frac{1}{2}\left\|z-x_{n}\right\|^{2}: z \in C\right\}, \\
y_{n}=\alpha_{n} z_{n}+\beta_{n} u_{n}+\gamma_{n} S z_{n}, \\
x_{n+1}=\vartheta_{n} h\left(x_{n}\right)+\left(1-\vartheta_{n}\right) y_{n}, \quad \forall n \geq 0,
\end{array}\right.
$$

where $u_{n} \in P_{T}\left(z_{n}\right)$. Let $\left\{\alpha_{n}\right\},\left\{\beta_{n}\right\},\left\{\gamma_{n}\right\},\left\{\lambda_{n}\right\}$ and $\left\{\vartheta_{n}\right\}$ satisfy the following conditions:

(i) $\left\{\vartheta_{n}\right\} \subset(0,1), \lim _{n \rightarrow \infty} \vartheta_{n}=0, \sum_{n=1}^{\infty} \vartheta_{n}=\infty$,

(ii) $\left\{\lambda_{n}\right\} \subset[a, b] \subset\left(0, \frac{1}{L}\right)$, where $L=\max \left\{2 c_{1}, 2 c_{2}\right\}$,

(iii) $\left\{\alpha_{n}\right\},\left\{\gamma_{n}\right\} \subset[a, 1) \subset(0,1), \alpha_{n}>\beta$ and $\alpha_{n}+\beta_{n}+\gamma_{n}=1$.

Then, the sequence $\left\{x_{n}\right\}$ converges strongly to $q \in \mathcal{F}$, which solves the variational inequality

$$
\langle q-h q, x-q\rangle \geq 0, \quad \forall x \in \mathcal{F} .
$$

As a consequence, we obtain the following result for single-valued mappings.

Corollary 3.3 Let $C$ be a nonempty closed convex subset of a real Hilbert space $H$, and let $f: C \times C \rightarrow \mathbb{R}$ be a monotone, continuous, and Lipschitz-type continuous bifunction. Suppose that $f(x, \cdot)$ is convex and subdifferentiable on $C$ for all $x \in C$. Let $T: C \rightarrow C$ be a nonexpansive mapping, and let $S: C \rightarrow C$ be a $\beta$-strict pseudo-contraction mapping. 
Assume that $\mathcal{F}=F(T) \cap F(S) \cap \operatorname{Sol}(f, C) \neq \emptyset$. Let h be a $k$-contraction of $C$ into itself. Let $\left\{x_{n}\right\},\left\{w_{n}\right\}$ and $\left\{z_{n}\right\}$ be sequences generated by $x_{0} \in C$ and by

$$
\left\{\begin{array}{l}
w_{n}=\arg \min \left\{\lambda_{n} f\left(x_{n}, w\right)+\frac{1}{2}\left\|w-x_{n}\right\|^{2}: w \in C\right\}, \\
z_{n}=\arg \min \left\{\lambda_{n} f\left(w_{n}, z\right)+\frac{1}{2}\left\|z-x_{n}\right\|^{2}: z \in C\right\}, \\
y_{n}=\alpha_{n} z_{n}+\beta_{n} T z_{n}+\gamma_{n} S z_{n}, \\
x_{n+1}=\vartheta_{n} h\left(x_{n}\right)+\left(1-\vartheta_{n}\right) y_{n}, \quad \forall n \geq 0 .
\end{array}\right.
$$

Let $\left\{\alpha_{n}\right\},\left\{\beta_{n}\right\},\left\{\gamma_{n}\right\},\left\{\lambda_{n}\right\}$ and $\left\{\vartheta_{n}\right\}$ satisfy the following conditions:

(i) $\left\{\vartheta_{n}\right\} \subset(0,1), \lim _{n \rightarrow \infty} \vartheta_{n}=0, \sum_{n=1}^{\infty} \vartheta_{n}=\infty$,

(ii) $\left\{\lambda_{n}\right\} \subset[a, b] \subset\left(0, \frac{1}{L}\right)$, where $L=\max \left\{2 c_{1}, 2 c_{2}\right\}$,

(iii) $\left\{\alpha_{n}\right\},\left\{\gamma_{n}\right\} \subset[a, 1) \subset(0,1), \alpha_{n}>\beta$ and $\alpha_{n}+\beta_{n}+\gamma_{n}=1$.

Then, the sequence $\left\{x_{n}\right\}$ converges strongly to $q \in \mathcal{F}$, which solves the variational inequality

$$
\langle q-h q, x-q\rangle \geq 0, \quad \forall x \in \mathcal{F} .
$$

\section{Application to variational inequalities}

In this section, we consider the particular Ky Fan inequality, corresponding to the function $f$, defined by $f(x, y)=\langle F(x), y-x\rangle$ for every $x, y \in C$ with $F: C \rightarrow H$. Then, we obtain the classical variational inequality

$$
\text { find } z \in C \text { such that }\langle F(z), y-z\rangle \geq 0, \forall y \in C \text {. }
$$

The set of solutions of this problem is denoted by $V I(F, C)$. In that particular case, the solution $y_{n}$ of the minimization problem

$$
\arg \min \left\{\lambda_{n} f\left(x_{n}, y\right)+\frac{1}{2}\left\|y-x_{n}\right\|^{2}: y \in C\right\}
$$

can be expressed as

$$
y_{n}=\operatorname{Proj}_{C}\left(x_{n}-\lambda_{n} F\left(x_{n}\right)\right) .
$$

Let $F$ be $L$-Lipschitz continuous on $C$. Then

$$
f(x, y)+f(y, z)-f(x, z)=\langle F(x)-F(y), y-z\rangle, \quad x, y, z \in C .
$$

Therefore,

$$
|\langle F(x)-F(y), y-z\rangle| \leq L\|x-y\|\|y-z\| \leq \frac{L}{2}\left(\|x-y\|^{2}+\|y-z\|^{2}\right),
$$

and, hence, $f$ satisfies Lipschitz-type continuous condition with $c_{1}=c_{2}=\frac{L}{2}$. Now, using Theorem 3.1, we obtain the following convergence theorem for finding a common element of the set of common fixed points of a strict pseudo-contractive mapping and a multivalued nonexpansive mapping and the solution set of the variational inequality problem. 
Theorem 4.1 Let $C$ be a nonempty closed convex subset of a real Hilbert space $H$, and let $F$ be a function from $C$ to $H$ such that $F$ is monotone and L-Lipschitz continuous on $C$. Let, $T: C \rightarrow C B(C)$ be a multivalued nonexpansive mapping, and let $S: C \rightarrow C$ be a $\beta$-strict pseudo-contraction mapping. Assume that $\mathcal{F}=F(T) \cap F(S) \cap V I(F, C) \neq \emptyset$ and $T(p)=\{p\}$ for each $p \in \mathcal{F}$. Let $h$ be a k-contraction of $C$ into itself. Let $\left\{x_{n}\right\},\left\{w_{n}\right\}$, and let $\left\{z_{n}\right\}$ be sequences generated by $x_{0} \in C$ and by

$$
\left\{\begin{array}{l}
w_{n}=\operatorname{Proj}_{C}\left(x_{n}-\lambda_{n} F\left(x_{n}\right)\right), \\
z_{n}=\operatorname{Proj}_{C}\left(x_{n}-\lambda_{n} F\left(w_{n}\right)\right), \\
y_{n}=\alpha_{n} z_{n}+\beta_{n} u_{n}+\gamma_{n} S z_{n}, \\
x_{n+1}=\vartheta_{n} h\left(x_{n}\right)+\left(1-\vartheta_{n}\right) y_{n}, \quad \forall n \geq 0,
\end{array}\right.
$$

where $u_{n} \in T z_{n}$. Let $\left\{\alpha_{n}\right\},\left\{\beta_{n}\right\},\left\{\gamma_{n}\right\},\left\{\lambda_{n}\right\}$ and $\left\{\vartheta_{n}\right\}$ satisfy the following conditions:

(i) $\left\{\vartheta_{n}\right\} \subset(0,1), \lim _{n \rightarrow \infty} \vartheta_{n}=0, \sum_{n=1}^{\infty} \vartheta_{n}=\infty$,

(ii) $\left\{\lambda_{n}\right\} \subset[a, b] \subset\left(0, \frac{1}{L}\right)$,

(iii) $\left\{\alpha_{n}\right\},\left\{\gamma_{n}\right\} \subset[a, 1) \subset(0,1), \alpha_{n}>\beta$ and $\alpha_{n}+\beta_{n}+\gamma_{n}=1$.

Then, the sequence $\left\{x_{n}\right\}$ converges strongly to $q \in \mathcal{F}$, which solves the variational inequality

$$
\langle q-h q, x-q\rangle \geq 0, \quad \forall x \in \mathcal{F} .
$$

\section{Competing interests}

The authors declare that they have no competing interests.

\section{Authors' contributions}

All authors contributed equally and significantly in writing this article. All authors read and approved the final manuscript.

\section{Author details}

'Department of Applied Mathematics, Mazandaran University of Science and Technology, Behshahr, Iran. ${ }^{2}$ Department of Mathematics, King Abdulaziz University, P.O. Box 80203, Jeddah, 21589, Saudi Arabia.

\section{Acknowledgements}

This article was funded by the Deanship of Scientific Research (DSR), King Abdulaziz University, Jeddah. Therefore, the second author acknowledges with thanks DSR, KAU for financial support. The authors thank the referees for their valuable comments and suggestions.

Received: 7 May 2013 Accepted: 25 July 2013 Published: 9 August 2013

\section{References}

1. Browder, FE, Petryshyn, WV: Construction of fixed points of nonlinear mappings in Hilbert spaces. J. Math. Anal. Appl. 20, 197-228 (1967)

2. Chidume, CE, Mutangadura, SA: An example on the Mann iteration method for Lipschitz pseudo-contractions. Proc Am. Math. Soc. 129, 2359-2363 (2001)

3. Scherzer, O: Convergence criteria of iterative methods based on Landweber iteration for solving nonlinear problems. J. Math. Anal. Appl. 194, 911-933 (1991)

4. Acedo, GL, Xu, HK: Iterative methods for strict pseudo-contractions in Hilbert spaces. Nonlinear Anal. 67, 2258-2271 (2007)

5. Marino, G, Xu, HK: Weak and strong convergence theorems for strictly pseudo-contractions in Hilbert spaces. J. Math. Anal. Appl. 329, 336-349 (2007)

6. Zhou, HY: Convergence theorems of common fixed points for a finite family of Lipschitz pseudo-contractions in Banach spaces. Nonlinear Anal. 68, 2977-2983 (2008)

7. Dhompongsa, S, Kaewkhao, A, Panyanak, B: Lim's theorem for multivalued mappings in CAT(0) spaces. J. Math. Anal. Appl. 312, 478-487 (2005)

8. Latif, A, Tweddle, I: Some results on coincidence points. Bull. Aust. Math. Soc. 59, 111-117 (1999)

9. Hussain, N, Khamsi, MA: On asymptotic pointwise contractions in metric spaces. Nonlinear Anal. 71, 4423-4429 (2009)

10. Abkar, A, Eslamian, M: Common fixed point results in CAT(0) spaces. Nonlinear Anal. 74, 1835-1840 (2011)

11. Espinola, R, Nicolae, A: Geodesic Ptolemy spaces and fixed points. Nonlinear Anal. 74, $27-34$ (2011)

12. Garcia-Falset, J, Llorens-Fuster, E, Moreno-Galvez, E: Fixed point theory for multivalued generalized nonexpansive mappings. Appl. Anal. Discrete Math. 6, 265-286 (2012) 
13. Markin, JT: Fixed points for generalized nonexpansive mappings in R-trees. Comput. Math. Appl. 62, 4614-4618 (2011)

14. Abkar, A, Eslamian, M: Fixed point theorems for Suzuki generalized nonexpansive multivalued mappings in Banach spaces. Fixed Point Theory Appl. 2010, Article ID 457935 (2010). doi:10.1155/2010/457935

15. Blum, E, Oettli, W: From optimization and variational inequalities to equilibrium problems. Math. Stud. 63, 123-145 (1994)

16. Flam, SD, Antipin, AS: Equilibrium programming using proximal-link algorithms. Math. Program. 78, 29-41 (1997)

17. Combettes, PL, Hirstoaga, SA: Equilibrium programming in Hilbert spaces. J. Nonlinear Convex Anal. 6, 117-136 (2005)

18. liduka, H, Yamada, I: A use of conjugate gradient direction for the convex optimization problem over the fixed point set of a nonexpansive mapping. SIAM J. Optim. 19, 1881-1893 (2009)

19. liduka, H, Yamada, I: A subgradient-type method for the equilibrium problem over the fixed point set and its applications. Optimization 58, 251-261 (2009)

20. Mainge, PE: A hybrid extragradient-viscosity method for monotone operators and fixed point problems. SIAM J. Control Optim. 47, 1499-1515 (2008)

21. Tada, A, Takahashi, W: Weak and strong convergence theorems for a nonexpansive mapping and an equilibrium problem. J. Optim. Theory Appl. 133, 359-370 (2007)

22. Takahashi, S, Takahashi, W: Viscosity approximation methods for equilibrium problems and fixed point problems in Hilbert spaces. J. Math. Anal. Appl. 331, 506-515 (2007)

23. Ansari, QH, Khan, Z: Densely relative pseudomonotone variational inequalities over product of sets. J. Nonlinear Convex Anal. 7(2), 179-188 (2006)

24. Ceng, LC, Ansari, QH, Yao, JC: Viscosity approximation methods for generalized equilibrium problems and fixed point problems. J. Glob. Optim. 43, 487-502 (2009)

25. Eslamian, M: Convergence theorems for nonspreading mappings and nonexpansive multivalued mappings and equilibrium problems. Optim. Lett. (2011). doi:10.1007/s11590-011-0438-4

26. Ceng, LC, Yao, JC: Hybrid viscosity approximation schemes for equilibrium problems and fixed point problems of infinitely many nonexpansive mappings. Appl. Math. Comput. 198, 729-741 (2008)

27. Ceng, LC, Yao, JC: A hybrid iterative scheme for mixed equilibrium problems and fixed point problems. J. Comput. Appl. Math. 214, 186-201 (2008)

28. Ceng, LC, Schaible, S, Yao, JC: Implicit iteration scheme with perturbed mapping for equilibrium problems and fixed point problems of finitely many nonexpansive mappings. J. Optim. Theory Appl. 139, 403-418 (2008)

29. Ceng, LC, Al-Homidan, S, Ansari, QH, Yao, JC: An iterative scheme for equilibrium problems and fixed point problems of strict pseudo-contraction mappings. J. Comput. Appl. Math. 223, 967-974 (2009)

30. Ceng, LC, Guu, SM, Yao, JC: Hybrid iterative method for finding common solutions of generalized mixed equilibrium and fixed point problems. Fixed Point Theory Appl. 2012, 92 (2012)

31. Ceng, LC, Ansari, QH, Schaible, S: Hybrid extragradient-like methods for generalized mixed equilibrium problems, systems of generalized equilibrium problems and optimization problems. J. Glob. Optim. 53, 69-96 (2012)

32. Ceng, LC, Yao, JC: A relaxed extragradient-like method for a generalized mixed equilibrium problem, a general system of generalized equilibria and a fixed point problem. Nonlinear Anal. 72, 1922-1937 (2010)

33. Ceng, LC, Petrusel, A, Yao, JC: Iterative approaches to solving equilibrium problems and fixed point problems of infinitely many nonexpansive mappings. J. Optim. Theory Appl. 143, 37-58 (2009)

34. Mastroeni, G: On auxiliary principle for equilibrium problems. In: Daniele, P, Giannessi, F, Maugeri, A (eds.) Equilibrium Problems and Variational Models. Kluwer Academic, Dordrecht (2003)

35. Anh, PN: A hybrid extragradient method extended to fixed point problems and equilibrium problems. Optimization 62, 271-283 (2013). doi:10.1080/02331934.2011.607497

36. Anh, PN: Strong convergence theorems for nonexpansive mappings and Ky Fan inequalities. J. Optim. Theory Appl. (2012). doi:10.1007/s10957-012-0005-x

37. Xu, HK: An iterative approach to quadratic optimization. J. Optim. Theory Appl. 116, 659-678 (2003)

38. Osilike, MO, Igbokwe, DI: Weak and strong convergence theorems for fixed points of pseudocontractions and solutions of monotone type operator equations. Comput. Math. Appl. 40, 559-567 (2000)

39. Mainge, PE: Strong convergence of projected subgradient methods for nonsmooth and nonstrictly convex minimization. Set-Valued Anal. 16, 899-912 (2008)

40. Dhompongsa, S, Kaewkhao, A, Panyanak, B: On Kirk strong convergence theorem for multivalued nonexpansive mappings on CAT(0) spaces. Nonlinear Anal. 75, 459-468 (2012)

41. Rockafellar, RT: Monotone operators and the proximal point algorithm. SIAM J. Control Optim. 14, 877-898 (1976)

42. Daniele, P, Giannessi, F, Maugeri, A: Equilibrium Problems and Variational Models. Kluwer, Norwell (2003)

doi:10.1186/1687-1812-2013-213

Cite this article as: Vahidi et al.: New iterative scheme with strict pseudo-contractions and multivalued

nonexpansive mappings for fixed point problems and variational inequality problems. Fixed Point Theory and Applications 2013 2013:213. 